\title{
Solid Waste Generation in Europe: Study of Affecting Factors Using Panel Data
}

\author{
Aggelopoulos Athanasios ${ }^{1}$, Komninos Dimitrios ${ }^{1}$, Dermatis Zacharias ${ }^{1}$, Anastasiou Athanasios ${ }^{1} \&$ Liargovas \\ Panagiotis $^{1}$ \\ ${ }^{1}$ Department of Economic Studies, University of Peloponnese, Greece \\ Correspondence: Anastasiou Athanasios, Assistant Professor of Department of Economic Studies, University of \\ Peloponnese, Greece.
}

Received: March 11, 2018

Accepted: March 27, 2018

Online Published: June 20, 2018

doi:10.5430/rwe.v9n1p77

URL: https://doi.org/10.5430/rwe.v9n1p77

\begin{abstract}
The factors that affect the quantity of solid waste inside the EU-28 but also in Switzerland and Norway for the period 1995 to 2014 are examined with the help of econometric model study based on panel data. The correlation between the quantity of solid waste generated and various factors is examined thoroughly and a separate reference of the consequences of the economic crisis on the quantity of the produced solid waste is presented. The results of the model study will be the basis for drawing conclusions of this article.
\end{abstract}

Keywords: waste management, supply and demand, green economy, economic crisis

\section{Introduction}

European legislation on waste management and recycling has been developed for the last thirty-five years and has resulted in significant improvements in their management practices and in the effort to tackle their volume.

However, the volumes of waste continue to rise, following the economic downturn. Each year two billion tons of waste are produced in the Member States of the European Union. According to OECD data, a $45 \%$ increase in the volume of waste is expected in 2020 compared to 1995.

In recent decades, waste management is an important issue in EU countries, as there is a significant increase in the habits of the inhabitants. According to Monte et al. (2008) «Due to the large volumes of waste generated, the high moisture content of the waste and the changing waste composition as a result of process conditions, recovery methods are usually expensive and their environmental impact is still uncertain. For this reason, it is necessary to continue research on different applications of wastes, while taking into account the environmental and economic factors of these waste treatments».

The purpose of this article is to examine the study of the factors affecting the quantity of the last twenty years in Europe with the help of econometric model based on panel data.

Initially a summary definition of the solid waste will be presented and the factors that affect the production of solid as recorded in literature, will be summarized. Afterwards the influence of these factors on the produced quantity of the solid waste will be investigated with the help of an econometric model. This model is based on panel data and examines the influence of these factors before and during the period of economic crisis. Finally the main conclusions of the article are excluded and questions for further research are set.

\section{Definition of Waste}

Waste, as defined by the Basel Convention, are "substances or objects that are discarded or are to be refused or are required to be refused by the national law provisions". More specifically, "waste are created when a product or material begins to be treated as waste, and managed as such. In this way, the waste includes materials produced, collected and then recycled, composted, incinerated with or without energy recovery or deposited in landfills" (OECD, 2005). In addition, the management and disposal of waste can have serious environmental impacts. Landfill, for example, takes up land space and may cause air, water and soil pollution, while incineration may result in emissions of air pollutants. 
Municipal solid waste (MSW) is any material that is undesirable and is not gas or liquid. The solid waste results from the production, transportation, processing and consumption of goods and poses risks to human health. MSW is also a major cause of degradation of the urban and natural environment with huge economic and social impacts (Darakas, 2014).

According to Lyons (2016) "Over the last two decades, European countries have increasingly shifted their focus with regard to municipal waste from disposal methods to prevention and recycling. Moving municipal waste management up the 'waste hierarchy' is essential to extract more value from resources while reducing the pressures on the environment and creating jobs».

In the category of waste are included all waste except waste in liquid phase without appreciable proportion of particulate pollutants (waste water) and gaseous pollutants.

\section{Factors Affecting the Quantity of the MSW}

Based on the characteristics of the factors that affect the amount of MSW, these can be grouped into two categories, the socio-economic and demographic factors. Socio-economic factors are income, gross domestic product (GDP), expenditure, taxation, employment, unemployment, the number of overnight stays of tourists, energy consumption, etc. Among them, income is the largest and most important factor in predicting production MSW, followed by GDP, expenditure and employment, respectively. Higher income represents a higher dynamic consumption and more waste produced. GDP growth leads to an increase in waste because the high prosperity increases consumer activities and business expansion (Purcell and Magette, 2009). Although GDP is not a measure of living standards, it is used for the provision of MSW at country level, because it is often consistently measurable and widely available (Ahmad, 2012, Kumar et al, 2011).

Consumer spending is a factor as important as GDP. The employment rate represents the wages and the purchasing power of citizens. The higher the ratio of workers to all citizens in every region, the more MSW generated due to the economic prosperity (Bandara et al., 2007). Along with the rapid rise in living standards and the growth experienced in recent years, the consumption needs of citizens with the accumulation of consumer goods increased as well. The refresh rates of these goods is much faster than before, resulting this way in the development of a country to be perceived by the public as an opportunity for consumption of more goods. This trend, however, is not always equated with a requirement to upgrade the quality of products that will not cause environmental problems after their use. Also, there is no strong product reuse, since people are resigned to their ability to acquire new ones (Gavrilakis, 2000).

Demographic factors include population density, population, number of households, urbanization, household size, age of people, education, the rate of infant mortality, life expectancy. The factors related to population (population, population density and the number of households) are the most widely and important factors for predicting production of MSW, followed by household size, urbanization, education and factors associated with the age.

The level of development of a country also affects the amount of MSW. In industrialized and economically developed countries, the quantity of waste produced per person is clearly greater than those of the least developed and poorest countries. Similar differences in the production of total waste observed between cities and province within a country. Inside the cities the waste produced per person are much more than those produced in the province (Gavrilakis, 2000)

The habits of urban residents and the province's influence the amount of MSW as well. Especially with regard to food waste, households in the province mainly that keep pets or are farming families, it is assumed that they use the waste to feed their animals. In many cases, indeed, some of the fermentable, are used to produce a kind of fertilizer. In this way they reduce largely the quantity of fermentable waste produced in the province. This takes place also in all regions and the least developed countries, where the main economic activity is the primary sector, i.e. agriculture and livestock. Of course, city dwellers do not have this feature, because they do not usually have gardens, fields and animals (Gavrilakis, 2000).

An additional feature is the type of services offered at each location. In the cities, especially in capitals, there are many public services that produce large amounts of waste paper. There is also a large number of shops that produce a lot of waste of cardboard, plastic, etc. Also, large industries, which are responsible for the production of a series of hazardous waste, are, in their vast majority, either within or close to major cities (Gavrilakis, 2000).

Finally, one of the key factors that contribute to both the quantity and composition of the waste produced is the reduction policies implemented, such as the processing of materials (e.g. recycling). 


\section{Econometric Model for MSW Management}

\subsection{Panel Data}

In order to appreciate the factors that affect the amount of waste generated, an econometric model that has as dependent variable the amount of waste per capita than 28 countries - EU members and Switzerland and Norway for the period 1995 to 2014 will be constructed. This period was the basis for the study due to the fact that documentary evidence of the quantity of waste for all countries is from 1995 onwards.

Because we want to run a model for all thirty countries and also we want to increase the range of observations, the model will be carried out using panel data (panel data). Therefore, we will have a total 20 annual observations of 30 countries collected in the form of panels. In this way the sample consists of 600 observations.

Panel data (panel data) are a special case of grouped data and recently used (especially after 1990) in modern econometrics. They are a set of data where a laminate sample (stratified unit) is shown over time. Therefore, panel data are also a combination of cross-section data and time series (Dritsakis, 2013). When the reference period of the entities are the same, then we have time balanced (balanced) dynamic cross sections, but we can analyze situations and with different time periods per entity. Using these data the multicollinearity between independent variables is limited, and the number of observations is increased, resulting in the rise of degrees of freedom that leads to improved efficiency of the valued coefficients and thus greater efficiency in the econometric estimation. Also, the use of this method makes possible the record of individual heterogeneity and, finally, the heteroskedasticity is limited.

In panel data analysis the basic model is expressed in the following way:

$$
Y_{i t}=\beta_{0}+\beta_{1} X_{i t, 1}+\beta_{\mathbf{2}} X_{i t, 2}+\cdots+\beta_{K} X_{i t, K}+\gamma_{i}+u_{i t}
$$

where $\boldsymbol{Y}_{i t}$ is the $\mathrm{t}$ observation of the $\mathrm{i}$ unit of the dependent variable $\mathrm{Y}$ for $\mathrm{i}=1,2, \ldots, \mathrm{N}$ and $\mathrm{t}=1,2, \ldots, \mathrm{T}, \boldsymbol{X}_{i t, \boldsymbol{I}}$ is the $\mathrm{t}$ observation of the explanatory variable $\mathrm{j}$ of $\mathrm{t}$ unit for $\mathrm{i}=1,2, \ldots, \mathrm{N}, \mathrm{t}=1,2, \ldots, \mathrm{T}$ and $\mathrm{j}=1,2, \ldots, \mathrm{K}, \boldsymbol{Y}_{\boldsymbol{i}}$ is the non observed variable, which does not vary over time for $\mathrm{i}=1,2, \ldots, \mathrm{N}$ and $\boldsymbol{u}_{i t}$ is the error term, which varies over time and from one unit to another, and to whom goes $\mathrm{E}\left\{\mathrm{u}_{\mathrm{it}}\right\}=0$.

In order for the model to be estimated, the nature of the non observed heterogeneity $Y_{i}$ should be determined, for which a distinction takes place between fixed effect, which is considered to be associated with the explanatory variables of the model and is identified as an additional parameter to estimate for each unit and random effect, which is considered as a random variable that correlates with the observed explanatory variables. Depending on whether the non-observed heterogeneity considered fixed or random, the model assessment methods are classified as fixed effects model or random effects model.

\subsection{Hausman Test}

In order to select the most appropriate method, the Hausman test should be performed. This control is implemented after the data values are inserted in the program and the dependent and independent variables of the model have been selected. Thereafter, the regression is performed with both effects models and is selected which one is most appropriate.

The assumptions made by the Hausman control are two. The first is the null hypothesis $\mathrm{H}_{0}$ where the $\beta_{\mathrm{fe}}$ coefficient of the fixed effects model is consistent but inefficient and the $\beta_{\text {re }}$ coefficient of the random effects model is consistent and effective. If the null hypothesis hypothesis $\mathrm{H}_{0}$ is accepted, the fixed effects method is more appropriate. The second is the alternative hypothesis $\mathrm{H}_{1}$ where the $\beta_{\mathrm{fe}}$ is consistent and the $\beta_{\mathrm{re}}$ inconsistent. If the alternative hypothesis $\mathrm{H}_{1}$ is accepted, the fixed effects method is more appropriate.

\section{Presentation of the Variables of the Econometric Model}

\subsection{Dependent Variable}

In this model, the dependent variable is the amount of waste per capita (waste_cap) and includes waste from residences, including bulky items, waste from small businesses and office buildings, waste collected from the streets and garbage bins, and waste from yards and gardens. In this amount is not included the waste from municipal sewage networks and treatment, as well as the waste from construction and demolition. The values correspond to the weight of the annual quantity of waste generated per capita data were taken from the OECD database and for those countries not belonging to the OECD (e.g. Bulgaria, Cyprus), taken from official government sources. 


\subsection{Explanatory Variables}

The following explanatory variables in relation to the quantity are included in the model, which have been found that affect the amount of waste. All these data were obtained from the database of the World Bank.

1)GDP_CAP: Per capita GDP is a measure of the total output of a country that receives the gross domestic product (GDP) and divides it by the number of people in the country. Per capita GDP is particularly useful when comparing one country with another, because it shows the relative performance of countries. The increase in per capita GDP implies economic growth and tends to be translated as an increase in productivity (World Bank). The data are in current US dollar prices. The coefficient of this variable is expected to be positive as there is a positive relationship between GDP growth and in the quantity of waste. Since our sample represents the last quarter during which evolved rapidly the waste management methods, there is a high probability that the coefficient is negative.

2)GNI_CAP: Per capita GNI (Gross National Income Per Capita - former per capita Gross Domestic Product) is the gross national income, denominated in US dollars with the method of the World Bank Atlas, divided by the population at mid-year. GNI is the sum of value added of all production units in the economy plus any product taxes (less subsidies) not included in the valuation of output plus net receipts of primary income (compensation of employees and property income) from abroad. GNI, calculated in national currency, is usually converted to US dollars at official exchange rates for comparisons across economies. To smooth price fluctuations and exchange rates, a special Atlas method of conversion is used by the World Bank. The method applies a conversion factor that puts the average exchange rate for a given year and the two preceding years, adjusted for differences in rates of inflation between the country, and by 2000, and the G-5 countries (France, Germany, Japan, United Kingdom, United States). Since 2001, these countries include the Euro area, Japan, the United Kingdom and the United States. The data are in current US dollar prices. This coefficientis expected to be slightly positive, as there is a high correlation with GDP.

3)EXP_CAP: The final consumption of households per capita (final consumption expenditure per capita) is calculated using private consumption in constant 2005 prices and population estimates of the World Bank. Final household consumption is the market value of all goods and services, including durable products (such as cars, washing machines, and home computers), purchased by households. It excludes housing markets, but includes imputed rent for owner-occupied dwellings. The data correspond to constant US dollar prices of 2005. The coefficientof this variable is expected to be positive, as the increase in consumption leads to an increase in the quantity of waste

4)POPULATION: The total population is based on the de facto definition, which counts all residents regardless of legal status or citizenship, except for refugees not permanently settled in the country of asylum. Prices shown are estimates the middle of each year. The coefficientis expected to be positive because of increasing population, growing and waste.

5)URBAN POPULATION: The urban population refers to people living in urban areas as defined by national statistical institutes (World Bank). Calculated based on the estimates of the World Bank's population. As the urban population grows, the living conditions, consumption patterns and life-style changes, resulting in generation of more waste. Therefore, the coefficient of the variable is expected to be positive.

6)POPULATION_DENSITY: The population density is the population of a country in the middle of the year divided by the area in square kilometers. The country's area is the total area of the country, excluding inland water bodies sector, national requirements for the continental shelf and the exclusive economic zone. In most cases the definition of inland water bodies includes major rivers and lakes (World Bank). As with the population, the coefficientis expected to be positive, as it has been observed that increasing population density corresponds to increased waste generation.

7)TOURISM: Internationally incoming tourists (overnight visitors) is the number of tourists who travel to a country other than that in which they have their habitual residence, but outside their usual environment for a period not exceeding 12 months and whose main purpose of visit other than the reward. The sources and collection methods for arrivals differ from country to country. In some cases, data from the statistics of the border (police, border stations etc.) and in other cases the data come from tourist accommodation (World Bank). The coefficient is expected to be positive, as it has been observed that tourism has a negative impact on waste production. In areas, namely, that large numbers of tourists, the amount of waste generated is growing. 
8)EMPLOYMENT RATE: The employment rate is the percentage of the population of a country engaged. Ages 15 and older are generally considered the work force of a country (World Bank). The coefficient is expected to be positive because of increasing the employment rate increases and the prosperity and consumption, and therefore the generation of waste.

9)DCRISIS: In addition to the real variables presented above, a dummy variable was also used. This dummy will cover the period of the crisis, namely the period from 2008 to 2014 and is used to study the effect of a period of crisis in the dependent variable. For the comments relating to the years 1995 and 2007, DCRISIS is 0 and the other set to 1 . The coefficient is expected to be negative, since the crisis has been a considerable drop in consumption, and therefore we expect a reduction of the produced waste quantity.

\section{Descriptive Statistics of Variables}

Table 1 shows the descriptive statistics of the variables used in the empirical analysis. The range data for each of the variables is large enough to adequately describe their influence on the amount of waste produced.

Table 1. Descriptive statistics of the variables

\begin{tabular}{cccccc}
\hline & WASTE CAP & GDP CAP & GNI CAP & EXP CAP & POPULATION \\
\hline MEAN & 489,37 & 27423,55 & 26245,73 & 14200,35 & 16924800 \\
\hline MEDIAN & 487,52 & 23144,12 & 22700,00 & 14744,26 & 8089346 \\
\hline MAXIMUM & 800,00 & 116664,26 & 104010,00 & 33275,42 & 82534176 \\
\hline MINIMUM & 256,00 & 1208,85 & 1300,00 & 1505,86 & 370433 \\
\hline SKEWNESS & 123,25 & 21400,69 & 19527,67 & 8313,34 & 21779444,07 \\
\hline KURTOSIS & $-0,03$ & 1,42 & 1,08 & 0,28 & 1,67 \\
\hline
\end{tabular}

\begin{tabular}{ccccc}
\hline & $\begin{array}{c}\text { POPULATION } \\
\text { DENSITY }\end{array}$ & TOURISM & $\begin{array}{c}\text { URBAN } \\
\text { POPULATION }\end{array}$ & $\begin{array}{c}\text { EMPLYMENT } \\
\text { RATE }\end{array}$ \\
\hline MEAN & 164,36 & 12401340 & 12299493 & 53,20 \\
\hline MEDIAN & 110,46 & 6710000 & 5470474 & 52,90 \\
\hline MAXIMUM & 1335,64 & 84726000 & 60929451 & 66,10 \\
\hline MINIMUM & 11,93 & 509000 & 336894 & 38,70 \\
\hline STD. DEV. & 224,54 & 16614810,28 & 16258032,34 & 5,99 \\
\hline SKEWNESS & 3,85 & 2,48 & 1,73 & 0,09 \\
\hline KURTOSIS & 15,68 & 6,08 & 1,71 & $-0,65$ \\
\hline
\end{tabular}

\section{Regression Models}

In order to examine the effect of each independent variable in the amount of waste various regression models created. Since several variables are highly correlated (Table 2) were six different regression models generated containing independent variables, which do not show a high correlation between them. For each model separately Hausman Test was performed to select the most appropriate method between fixed and random effects. The econometric software used to run this regression was EViews 7. 
Table 2. Corellation between the variables

\begin{tabular}{ccccccccc}
\hline & $\begin{array}{c}\text { EMPL. } \\
\text { RATE }\end{array}$ & $\begin{array}{c}\text { EXP } \\
\text { CAP }\end{array}$ & $\begin{array}{c}\text { GDP } \\
\text { CAP }\end{array}$ & $\begin{array}{c}\text { GNI } \\
\text { CAP }\end{array}$ & POPUL. & $\begin{array}{c}\text { POPUL. } \\
\text { DENSITY }\end{array}$ & TOURISM & $\begin{array}{c}\text { URBAN } \\
\text { POPUL. }\end{array}$ \\
\hline $\begin{array}{c}\text { EMPL. } \\
\text { RATE }\end{array}$ & 1 & 0.516888 & 0.478785 & 0.518369 & -0.171844 & -0.125777 & -0.252784 & -0.147481 \\
\hline EXP CAP & 0.516888 & 1 & 0.887933 & 0.909447 & 0.191895 & 0.045165 & 0.199055 & 0.235597 \\
\hline GDP CAP & 0.478785 & 0.887933 & 1 & 0.976421 & 0.034305 & 0.010802 & 0.084249 & 0.072068 \\
\hline GNI CAP & 0.518369 & 0.909447 & 0.976421 & 1 & 0.077839 & 0.013333 & 0.124919 & 0.119147 \\
\hline POPUL. & -0.171844 & 0.191895 & 0.034305 & 0.077839 & 1 & 0.018150 & 0.764610 & 0.994108 \\
\hline POPUL. & & & & & & & & \\
DENSITY & -0.125777 & 0.045165 & 0.010802 & 0.013333 & 0.018150 & 1 & -0.057154 & 0.033065 \\
\hline TOURISM & -0.252784 & 0.199055 & 0.084249 & 0.124919 & 0.764610 & -0.057154 & 1 & 0.777024 \\
\hline $\begin{array}{c}\text { URBAN } \\
\text { POPUL. }\end{array}$ & -0.147481 & 0.235597 & 0.072068 & 0.119147 & 0.994108 & 0.033065 & 0.777024 & 1 \\
\hline
\end{tabular}

\section{Regression Results}

In each element of Table 3 are indicated the two key figures describing the relationship of each independent variable and the dependent variable, as derived from empirical research.

The first number of each table element represents the size of the correlation between independent and dependent variable called correlation coefficient (Coefficient $b$ ).

Just below this number, indicated in brackets the level of statistical significance (P-value) of each effect.

The ratio of the variation of the dependent variable explained by the regression is called coefficient of determination

$\mathrm{R}^{2}$ and appears on the penultimate line of the table.

The last line of the table shows the number of observations.

Table 3. Regression results

\begin{tabular}{|c|c|c|c|c|c|c|c|}
\hline \multirow{2}{*}{\multicolumn{2}{|c|}{$\begin{array}{l}\text { DEPENDENT VARIABLE: } \\
\text { WASTE CAP }\end{array}$}} & \multicolumn{6}{|c|}{ REGRESSION } \\
\hline & & EQ01 & EQ02 & EQ03 & EQ04 & EQ05 & EQ06 \\
\hline \multirow{12}{*}{ 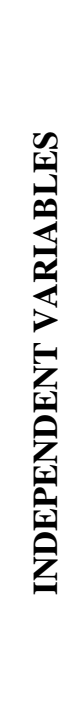 } & \multirow{2}{*}{ GDP CAP } & 0,0007 & 0,0007 & - & - & - & - \\
\hline & & 0,0006 & 0,0007 & - & - & - & - \\
\hline & \multirow{2}{*}{ EXP CAP } & - & - & 0,0076 & 0,0064 & - & - \\
\hline & & - & - & 0,0000 & 0,0000 & - & - \\
\hline & \multirow{2}{*}{ GNI CAP } & - & - & - & - & 0,0007 & 0,0007 \\
\hline & & - & - & - & - & 0,0008 & 0,0019 \\
\hline & \multirow{2}{*}{ POPULATION } & - & $-8,97 \mathrm{E}-06$ & - & $-7,85 \mathrm{E}-06$ & - & $-9,05 \mathrm{E}-06$ \\
\hline & & - & 0.0020 & - & 0.0062 & - & 0,0018 \\
\hline & \multirow{2}{*}{$\begin{array}{c}\text { URBAN } \\
\text { POPULATION }\end{array}$} & $-7,85 \mathrm{E}-06$ & - & $-9,25 \mathrm{E}-06$ & - & $-8,20 \mathrm{E}-06$ & - \\
\hline & & 0,0005 & - & 0,0000 & - & 0,0003 & - \\
\hline & \multirow{2}{*}{$\begin{array}{l}\text { POPULATION } \\
\text { DENSITY }\end{array}$} & 1,2588 & - & 1,2336 & - & 1,2873 & - \\
\hline & & 0,0000 & - & 0,0000 & - & 0,0000 & - \\
\hline
\end{tabular}




\begin{tabular}{ccccccc}
\hline \multirow{2}{*}{ TOURISM } & - & $2,23 \mathrm{E}-06$ & - & $1,62 \mathrm{E}-06$ & - & $2,18 \mathrm{E}-06$ \\
\cline { 2 - 6 } & - & $\mathbf{0 , 0 1 9 5}$ & - & $\mathbf{0 , 0 9 3 4}$ & - & $\mathbf{0 , 0 2 4 5}$ \\
\hline EMPLOYMENT & - & 4,2076 & - & 3,3480 & - & 4,4042 \\
\cline { 2 - 7 } RATE & - & $\mathbf{0 , 0 0 0 0}$ & - & $\mathbf{0 , 0 0 0 3}$ & - & $\mathbf{0 , 0 0 0 0}$ \\
\hline $\mathbf{R}^{2}$ & $\mathbf{0 , 8 7 1 7}$ & $\mathbf{0 , 8 6 6 3}$ & $\mathbf{0 , 8 7 7 6}$ & $\mathbf{0 , 8 6 8 7}$ & $\mathbf{0 , 8 7 6 9}$ & $\mathbf{0 , 8 6 5 9}$ \\
\hline OBSERVATIONS & 600 & 600 & 600 & 600 & 600 & 600 \\
\hline
\end{tabular}

8.1 Regression Results With Dummy Variable

Table 4. Regression results with dummy variable

\begin{tabular}{|c|c|c|c|c|c|c|c|}
\hline \multirow{2}{*}{\multicolumn{2}{|c|}{$\begin{array}{l}\text { DEPENDENT VARIABLE: } \\
\text { WASTE CAP }\end{array}$}} & \multicolumn{6}{|c|}{ REGRESSION } \\
\hline & & EQ0101 & EQ0201 & EQ0301 & EQ0401 & EQ0501 & EQ0601 \\
\hline \multirow{18}{*}{ 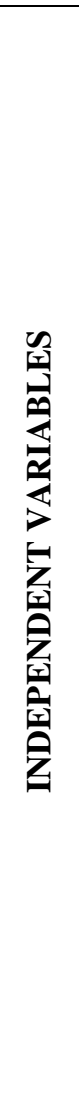 } & \multirow{2}{*}{ GDP CAP } & 0,0012 & 0,0011 & - & - & - & - \\
\hline & & 0,0000 & 0,0000 & - & - & - & - \\
\hline & \multirow{2}{*}{ EXP CAP } & - & - & 0,0101 & 0,0084 & - & - \\
\hline & & - & - & 0,0000 & 0,0000 & - & - \\
\hline & \multirow{2}{*}{ GNI CAP } & - & - & - & - & 0,0014 & 0,0012 \\
\hline & & - & - & - & - & 0,0000 & 0,0001 \\
\hline & \multirow{2}{*}{ POPULATION } & - & $-8,94 \mathrm{E}-06$ & - & $-7,39 \mathrm{E}-06$ & & $-9,10 \mathrm{E}-06$ \\
\hline & & - & 0,0019 & - & 0,0098 & & 0,0016 \\
\hline & \multirow{2}{*}{$\begin{array}{c}\text { URBAN } \\
\text { POPULATION }\end{array}$} & $-6,47 \mathrm{E}-06$ & - & $-7,25 \mathrm{E}-06$ & - & $-7,12 \mathrm{E}-06$ & - \\
\hline & & 0,0044 & - & 0,0010 & - & 0,0018 & - \\
\hline & \multirow{2}{*}{$\begin{array}{l}\text { POPULATION } \\
\text { DENSITY }\end{array}$} & 1,3034 & - & 1,3497 & - & 1,3479 & - \\
\hline & & 0,0000 & - & 0,0000 & - & 0,0000 & - \\
\hline & \multirow{2}{*}{ TOURISM } & - & 2,76E-06 & - & $2,10 \mathrm{E}-06$ & - & $2,61 \mathrm{E}-06$ \\
\hline & & - & 0,0047 & - & $\mathbf{0 , 0 3 1 7}$ & - & 0.0078 \\
\hline & \multirow{2}{*}{$\begin{array}{l}\text { EMPLOYMENT } \\
\text { RATE }\end{array}$} & - & 3,6935 & - & 2,7576 & - & 3,9433 \\
\hline & & - & 0,0001 & - & 0,0040 & - & 0,0000 \\
\hline & \multirow{2}{*}{ DCRISIS } & $-17,3531$ & $-14,0138$ & $-18,9144$ & $-12,5173$ & $-20,1854$ & $-14,8648$ \\
\hline & & 0,0012 & 0,0131 & 0,0001 & 0,0130 & 0,0003 & 0,0117 \\
\hline & $\mathbf{R}^{2}$ & 0,8741 & 0,8677 & 0,8810 & 0,8701 & 0,8745 & 0,8674 \\
\hline & BSERVATIONS & 600 & 600 & 600 & 600 & 600 & 600 \\
\hline
\end{tabular}

\section{Comments on the Results}

Based on the results of the regression that are shown in Tables 3 and 4, we can conclude that all regression models showed a highly satisfactory coefficient of determination $\mathrm{R}^{2}$ of about $87 \%$. Therefore they represent good adjustment to the data and interpret at a large extent the overall variability of the dependent variable. Practically, the amount of waste generated is interpreted by $87 \%$ of the sample data and $13 \%$ of the residues. In all of the cases, the suitable method was considered that of fixed effects through Hausman Test that we applied in each case. 
Regarding the explanatory variables of the model, we can highlight that the coefficients of the variables related to GDP (gdp_cap), national income (gni_cap) and private consumption (exp_cap), which exhibit high correlation between them and this is why we ran them in different models, have the same sign and they are all statistically significant even at the $1 \%$ level. Their positive sign confirms our prediction that we made, that increasing the value of these factors increases the amount of waste generated. The sign of the variables and their significance has not changed even at the models that a dummy was used for the crisis period.

The variables that refer to the population (population) and urban population (urban_population), which had the highest correlation with each other, contrary to our initial forecast, they have a negative sign but this is again statistically significant at $1 \%$ level. The same applies to models that the dummy was used for the crisis period. Conversely, the variables related to the population density (population_density), and the employment rate (employment_rate) confirmed the positive relationship they have with the amount of waste generated. The significance of the coefficients in both cases is significant at the $1 \%$ level. The variable of tourism (tourism) confirmed the positive relationship with the quantity of waste generated. The significance of the coefficient in this case is significant in 1\% level models EQ0201 and EQ0601, at 5\% models EQ02 and EQ06, EQ0401) and at 10\% in EQ04 model. Still it remains statistically significant variable in all cases. Finally, the negative sign of the dummy variable confirms this prediction made, namely that during the crisis period in which the welfare of the countries was decreased, the quantity of waste also declined. The dummy was observed that was significant and that a $1 \%$ level.

Generally we can emphasize that our model had high explanatory power and consisted of variables that were statistically significant at all lower significance level. In most cases they confirmed the forecasts for their signs, predictions that were derived from previous studies.

\section{Conclusion}

This study shows that the socio-economic characteristics of people explain almost all the variations in the solid waste generation. This method, as presented in this paper, aimed to highlight the relationship between socio-economic indicators, the standard of living of citizens, and the development of countries as a result of waste generation. In the future, strategic decisions to be taken on waste management will depend on any taxes that will be imposed on material recycling and waste management. This special management tax will be proportional to the production of waste, which depends on the indicators we analyzed. The benefit of special management taxes will contribute to state revenues as well as to environmental protection.

\section{References}

Ahmad, K. (2012). A system dynamics modeling of municipal solid waste management systems in Delhi. Int. J. Renew. Energy Technol., 1, 628-641.

Bandara, N.J.G.J., Hettiaratchi, J.P.A., Wirasinghe, S.C., \& Pilapiiya, S. (2007). Relation of waste generation and composition to socio-economic factors: a case study. Environ. Monit. Assess., 135, 31-39. https://doi.org/10.1007/s10661-007-9705-3

Darakas, E. (2014). Municipal Solid Waste Management. Aristoteleio University of Thessaloniki.

Dritsakis, C., \& Dritsakis, M. (2013). Introduction to the Econometry - Kleidarithmos.

Gavrilakis, K. (2000). Waste: Prob lems and their confrontation. Ministry of Education of Greece.

Kumar, J.S., Subbaiah, K.V., \& Rao, P.V.V.P. (2011). Prediction of municipal solid waste with RBF Net Work - A case study of Eluru, A.P., India. Int. J. Innovat., Manage. Technol., 2, 238-243.

Lyons, R. (2016). Municipal waste management across European countries, Sustainable Development Research Network.

Monte, M.C., Fuente, E., Blanco, A., \& Negro, C. (2009). Waste management from pulp and paper production in the European Union, Waste Management, 29(1), 293-308. https://doi.org/10.1016/j.wasman.2008.02.002

OECD. (2005). Environmentally Related Taxes database. Retrieved from www.oecd.org 